\title{
Research on the Status Quo and Optimization Strategy of China's Innovative Financial Resources Allocation
}

\author{
Chao Zeng \\ Science and Technology College \\ Jiangxi Normal University \\ Nanchang, China
}

\author{
Yi Zhou* \\ Business College \\ Jiangxi Normal University \\ Nanchang, China \\ jxsdjh@vip.sina.com
}

\begin{abstract}
Resource allocation is the process of selecting, arranging, and matching scarce resources between various possible uses for optimal efficiency. Innovative financial resources refer to the financial resources of all aspects invested in innovation activities. In the current innovation activities, high capital investment has become an important guarantee for the smooth development of innovation activities. This paper looks at the relevant data of China Statistical Yearbook, China Science and Technology Statistical Yearbook. There are few analysis of the direction of innovative financial resources. Therefore, this paper compares and analyzes the status quo of innovative financial resources input, and finds that China's innovative financial resources allocation has weak input intensity, uneven distribution of the main body, insufficient government guidance, and obvious regional disparity. Based on this, a corresponding solution strategy is proposed to provide reference for the optimal allocation of innovative resources in China.
\end{abstract}

Keywords-Innovative financial resources allocation; Status quo; Optimization strategy

\section{INTRODUCTION}

Innovative financial resources refer to funds that can effectively support regional innovation activities. Under the rapid development of science and technology, high investment in innovative financial resources has become a necessary guarantee for the smooth development of innovative activities. The source, quantity and structure of innovative financial resources input will directly affect the scale, process and level of innovation activities, thus affecting the overall innovation capability of the region. The quantity, source channels and distribution ratio of innovative financial resources directly determine and influence the scale and nature of innovation activities. The source structure of innovative financial resources determines the role of innovation entities in promoting the development of regional innovation capabilities In recent years, UNESCO has used R\&D funds as the main statistical indicator for science and technology funding and innovation investment.[1] This paper regards R\&D expenditure as an indicator of innovative financial resources.

\section{Analysis Of The Status Quo Of China's InNOvative FINANCIAL RESOURCES ALLOCATION}

\section{A. Total Configuration}

In 2016, the total R\&D expenditure was 1567.675 billion yuan, an increase of 150.687 billion yuan or $10.6 \%$ over the previous year. The growth rate was $1.7 \%$ higher than that of the previous year; the overall upward trend, of which the growth rate from 2008 to 2011 was more obvious. After 2012, China's R\&D expenditures showed a downward trend. The R\&D expenditure intensity is an important indicator used by the international community to measure the degree of technological innovation in a country or region). The value in 2016 is 2.11 . Increased by $0.05 \%$ in the previous year. In general, in 2016, China's science and technology funding has increased, and research and experimental development (R\&D) funding, research and experimental development (R\&D) funding intensity has steadily increased. However, compared with developed countries, there is still room for improvement. The economies with the highest $R \& D$ expenditures in the world are Israel $(4.4 \%)$, Finland $(3.9 \%)$, South Korea $(3.7 \%)$, Sweden (3.4\%), Japan (3.3\%), the United States $(2.8 \%)$, and Germany (2.8). \%) and other countries. In 2016, China's industrial enterprises invested a total of 1094.47 billion yuan in $\mathrm{R} \& \mathrm{D}$ expenditure, an increase of 93.08 billion yuan over the previous year, an increase of $9.30 \%$, an increase of $82.6 \%$ over 2011. The overall trend is on the rise. But overall, the growth rate has been declining year by year, from $20.13 \%$ in 2012 to $9.3 \%$ in 2016 .

\section{B. Main Configuration}

In 2016, according to the main activity of the activities, the expenditure of various enterprises was 1,124.4 billion yuan, an increase of $11.6 \%$ over the previous year; the expenditure of the government's research institutions was 226.02 billion yuan, an increase of $5.8 \%$; the expenditure of higher education institutions was 107.22 billion yuan, an increase of $7.4 \%$. The proportion of enterprises, government-owned research institutions, and higher education institutions accounted for $77.5 \%, 14.4 \%$, and $6.8 \%$, respectively. From 2006 to 2016 , the internal expenditure of China's R\&D expenditures in research institutions and institutions of higher learning declined, from $18.89 \%$ to $15.10 \%$ and $9.22 \%$ to $7.00 \%$ respectively; the 
internal expenditure of $\mathrm{R} \& \mathrm{D}$ funds invested in enterprises increased. The trend rose from $71.08 \%$ to $76.80 \%$. It can be found that enterprises have gradually become the main body of innovation resource allocation in China, and the proportion of institutions of higher learning and research institutions has been declining year by year.

\section{Phase Configuration}

In terms of the types of activities in 2016, the national basic research funds were 82.289 billion yuan, up 14.9\% over the previous year; the applied research funds were 161.045 billion yuan, up 5.4\%; the experimental development funds were 1324.336 billion yuan, up $11.1 \%$. The proportion of basic research, applied research and experimental development funds was $5.2 \%, 10.3 \%$ and $84.5 \%$ respectively. China pays special attention to the research funding of experimental development and ignores the input of basic research. Compared with 2006, the proportion of China's R\&D expenditures to basic research is not much different; the proportion of input to applied research has dropped from $16.28 \%$ to $10.27 \%$; on the contrary, the proportion of input to experimental development has increased from $78.53 \%$ to $84.48 \%$, indicating that China Most of the R\&D expenditures have been invested in the experimental development. From 2006 to 2016, there has been an upward trend. In contrast, applied research has declined, and basic research has been running smoothly.

\section{Area Configuration}

In 2016, China's R\&D expenditures were 1567.675 billion yuan, and the eastern, central, western and northeastern regions were1068.938, 237.814, 194.434 and 66.489 billion yuan .respectively, accounting for $68.19 \%, 15.17 \%, 12.40 \%$ and $4.24 \%$. The proportion of R\&D expenditure in the eastern region is much larger than that in the central region, the western region and the northeast region. It can be seen that the allocation of innovative financial resources in China varies greatly in different regions. And R\&D funding is concentrated in Guangdong, Shandong, Zhejiang, Shanghai, Beijing and other places. Among them, the internal expenditure of R\&D expenditure is ranked first in Jiangsu, second in Guangdong and third in Shandong; the basic research investment ranks first in Beijing, second in Shanghai and third in Guangdong; the investment in experimental development ranks first in Jiangsu and second in Guangdong. Shandong third. The data shows that Jiangsu and Guangdong have rich financial resources, and Beijing has invested more in basic research; while innovative financial resources such as Xinjiang, Qinghai, Ningxia, Gansu and Hainan are weak. In 2016, the R\&D expenditure intensity ranking was ranked first in Beijing, second in Shanghai and third in Tianjin. It can be seen that the internal expenditures of $R \& D$ expenditures in China are not balanced in various regions, and the gap is large. In 2016, the internal expenditure of R\&D expenditures of industrial enterprises in China was 1094.466 billion yuan, and the eastern, central, western and northeastern regions were $748.439,189.693,114.192$ and 42.142 yuan respectively, accounting for $68.38 \%, 17.33 \%, 10.43 \%$ and $3.85 \%$. The proportion of internal expenditures of $\mathrm{R} \& \mathrm{D}$ funds in the eastern region is much larger than that in the central region, the western region and the northeast region. It can be seen that the allocation of innovative financial resources of industrial enterprises in China is very different in different regions. And R\&D funding is concentrated in Guangdong, Shandong, Jiangsu, Zhejiang, Shanghai, Beijing and other places. Among them, R\&D expenditures are ranked first in Guangdong, second in Jiangsu, and third in Shandong. The expenditures for experimental development are ranked first in Jiangsu, second in Guangdong, and third in Shandong. The daily expenditures are ranked first in Guangdong, second in Jiangsu, and third in Shandong. The data shows that Jiangsu, Guangdong, and Shandong have rich financial resources, while innovative financial resources such as Xinjiang, Qinghai, Ningxia, Gansu, and Hainan are weak. It can be seen that the internal expenditures of $R \& D$ expenditures of industrial enterprises in China are not balanced in various regions, and the gap is large.

\section{Existing Problems In The Allocation Of InNovative FINANCIAL RESOURCES IN CHINA}

\section{A. Weak Input Intensity}

Through the analysis of China's R\&D investment status, it was found that in 2016, the total R\&D expenditure was 1567.675 billion yuan, an increase of 150.687 billion yuan or $10.6 \%$ over the previous year. The growth rate was 1.7 percentage points higher than the previous year; the $R \& D$ expenditure intensity was $2.11 \%$, an increase of $0.05 \%$ over the previous year. China's R\&D expenditures have steadily increased in recent years, and the proportion of $R \& D$ expenditures to GDP has also increased significantly. However, compared with the R\&D expenditure intensity of the United States, Japan and other technological innovation powers, China's R\&D expenditure intensity is still at a low level. China needs to increase $R \& D$ expenditures, increase the intensity of $\mathrm{R} \& \mathrm{D}$ expenditures, and contribute to sustainable economic growth.

\section{B. Uneven Configuration of the Main Body}

Enterprises are the main body of technological innovation, the government is the main body of institutional innovation, and the improvement of regional innovation capability is the result of the simultaneous advancement of technological innovation and institutional innovation. At present, the role of the main body of innovation resource allocation in China has always been misplaced and absent. Can become a true technological innovation subject, which is the trace of the drawbacks of the traditional planned economic system, but more importantly, because the modern enterprise system has not yet been fully established, the market awareness and competition awareness of the enterprise is not strong, and the requirements for the improvement of innovation ability are not strong. This further exacerbates the spread of the problem of the lack of status of innovation subjects, which in turn affects the ability of enterprises to allocate innovative resources. In the process of the allocation of innovative resources, the government has played a role that should not be played. It has not fully played the role of the main body of institutional 
innovation, and has not provided corresponding institutional guarantees for the establishment of the main body of technological innovation. The misplacement of the status of government innovation has hindered the reform of the innovation system and the improvement of the innovation system, curbed the free growth of enterprises, weakened the main position of enterprises in technological innovation, and affected the improvement of regional innovation capabilities.

\section{Government Guidance Is Not Enough}

The data shows that the proportion of China's innovative financial resources allocation in basic research, applied research and experimental development research is large, showing an imbalance. And the momentum that has been rising in recent years has warned us that we should also pay attention to basic research. Government funds can play a guiding role in the development of certain types of enterprises or industries through policy inclination. Too low a government investment scale will be difficult to effectively guide the development of enterprise innovation capabilities. At present, China's innovative financial resources Resources are also showing an imminent form of government guidance. Although some studies have shown that government R\&D expenditures have certain guiding and demonstration effects on enterprises and other departments to some extent, due to the large differences in $R \& D$ resources of different industries in different regions, the difference in the driving effect of the government in R\&D investment is also higher. Large areas, especially those with low guidance effects, still have great potential. At this stage, there is still room for improvement in the guiding effect of government R\&D funding. Thereby improving the current imbalance of $R \& D$ expenditures in basic research, applied research and experimental development. At present, China's intellectual property evaluation system has low reliability and poor validity, which increases the risk of high-tech transformation and investment. Moreover, China does not have a good environment for the protection of intellectual property rights. Enterprises lack awareness of intellectual property rights in development. Technicians are afraid of technology leaks and are unwilling to cooperate and communicate with others. The government has not guided enough in this regard, which is largely Reduced the speed of results conversion.

\section{The Regional Gap Is Obvious}

In 2016, there were 6 provinces (cities) with more than 100 billion yuan, accounting for $12.98 \%, 12.93 \%, 9.99 \%, 9.47 \%$, $7.21 \%$, and $6.69 \%$, respectively, in Guangdong, Jiangsu, Shandong, Beijing, Zhejiang, and Shanghai. There are 8 provinces (cities) with R\&D expenditures exceeding the national average, namely Beijing, Shanghai, Tianjin, Jiangsu, Guangdong, Zhejiang, Shandong and Shaanxi. Relevant data show that R\&D expenditures are significantly different in the eastern, central and western regions. The eastern region is far higher than the central and western regions in terms of R\&D expenditure, $R \& D$ expenditure per person, $R \& D$ project funding, and internal expenditure on $R \& D$ expenditure per unit project. The R\&D expenditures in Xinjiang and Guizhou in the western region are relatively insufficient, which restricts the efficiency and technological progress of R\&D activities, affects the efficiency of resource allocation in various regions and China's economic growth.[2]

\section{The Strategic Orientation Of The Allocation Of INNOVATIVE FINANCIAL RESOURCES IN CHINA}

\section{A. Improving the Intensity of Resource Input}

China's investment in R\&D funds is relatively low. Although there has been an upward trend in recent years but the growth is slow, it is necessary to continue to increase $R \& D$ expenditure.[3] At the same time, it also shows that R\&D expenditures are redundant in some regions. Therefore, in the case that the total amount and intensity of R\&D expenditures in China are difficult to reach the level of developed countries in the short term, each region should avoid the imbalance of resources caused by input imbalance. Local governments should continue to support a large number of experimental developments of enterprises, pay attention to basic research inputs, and increase the intensity of resource input.

\section{B. Correcting the Position of the Company}

Innovation is not only technological innovation, but also knowledge innovation, institutional innovation and service innovation. Different innovations have different main bodies. The main body of technological innovation is enterprises. The main body of knowledge innovation is universities and scientific research institutions. The main body of institutional innovation is government. The main body of service innovation is various types of innovative service organizations. The strengthening of the resource allocation ability of the innovation subject depends on all kinds of innovation entities to truly fulfill their respective roles and complement each other and form a complete system. Making enterprises become the mainstay of technological innovation is the key to the construction and improvement of China's regional innovation system. To become the main body of technological innovation, enterprises must have corresponding innovation systems and innovative capabilities. Enterprises should consciously and continuously improve their innovation capabilities and accelerate the establishment of a modern enterprise system, thus forming an innovation system that is compatible with the innovation capabilities of enterprises. In the process of establishing the main position of enterprise technology innovation, enterprises must clarify the relationship with the government, and truly position themselves in the main body of the market and the main body of technological innovation, no longer attached to the government, but through the reform of the government. On the basis of the established system, the main position is constantly established, replacing the government's previous major functions in technological innovation.

\section{Strengthening the Role of Government Guidance}

Under the guidance of the government, the goal is to establish a national system with enterprises as the mainstay, but at present it is necessary to overcome the separation of science and technology and economy, as well as the internal division of science and technology systems and economic systems, as the leader of R\&D activities of innovative entities. 
The government must fully tap, utilize and utilize the technological advantages of universities and research institutes that are the main bearers of existing R\&D activities, and use the innovative resources of universities to achieve an organic combination with the production factors of enterprises, while paying attention to the innovative financial resources of basic research. Is an effective way to achieve optimal allocation of innovative resources.[4]

\section{Adjusting Regional Resource Configuration}

The innovation resource allocation is related to the improvement of enterprise innovation efficiency, the improvement of regional economic development quality, and the formation of regional sustainable innovation capability. Therefore, it is essential to optimize the allocation of innovation resources. There are different modes of innovation resource allocation, based on regional innovation. The platform's innovative resource allocation is based on the basic ideas of utilizing existing stock resources, forming and developing new innovative resources, through the early stage of innovation resource survey and strategic research, platform management-centered innovation resource integration, enterprise-centric The innovation activities and the integration of innovation platforms, the transformation and application of innovation results, the evaluation of innovation effects, the innovation of results and the process of knowledge storage, optimize the efficiency of innovation resource allocation in the region, is of great significance to practice. The government should actively play its adjustment. Role, the rational allocation of innovative financial resources between different regions. In areas with low investment in innovative financial resources and less R\&D activities, it is necessary to increase investment in innovative financial resources and give corresponding policy incentives to stimulate the enthusiasm of independent innovation.

\section{CONCLUSION}

At present, technological innovation has shown a new development trend under the new round of scientific and technological revolution. In recent years, innovation-driven development, mass entrepreneurship, and innovation have been frequently mentioned in official reports. It can be seen that the country and regions have taken innovation to new heights. However, it seems that it is no longer possible to rely on increasing investment in science and technology innovation to improve China's innovation performance. Compared with developed countries, China has a big gap in the level of scientific and technological innovation output. Combine other innovative resources, improve the allocation of innovative financial resources, and improve the overall allocation efficiency of innovation resources, from improving the intensity of resource input, correcting the status of enterprises, strengthening the role of government guidance, and adjusting regional resource allocation.

\section{ACKNOWLEDGMENT}

This paper is one of the research results of Research on the Difference of Enterprise Innovation Resource Allocation System under Supply Side Reform in the Research project of Humanities and Social Sciences in Universities in Jiangxi Province.

\section{REFERENCES}

[1] D. Guo, "The situation, problems and Countermeasures of R\&D investment in China," Shanghai statistics, vol. 05, pp. 14-16, 2003.

[2] Y.J. Li and C.Z. Wang, "Comparative Analysis of Resource Allocation Efficiency - A Case Study of China's Regional Higher Education Resources," J. Soft Science, vol. 28 , pp. 22-26, 2014.

[3] M.M. Li and H.J. Xiao, "Fiscal Policy, Enterprise R\&D Investment and Technological Innovation Capability_An Empirical Study Based on Strategic Emerging Industries Listed Companies," Management Review, vol. 08, pp. 135-144, 2014.

[4] F. Fan and J.Q. Zhang, "Study on Spatial Spillover Effect of Regional Science and Technology Resource Allocation under Environmental Constraints," J. Urbanization and Regional Development, vol. 4 , pp. 71$80,2016$. 